\title{
Large-scale Vegetation Features of the Amazon Basin Visible on the JERS-1 Low-water Amazon Mosaic
}

\author{
Laura L. Hess', Evlyn M.L.M. Novo ${ }^{2}$, Dalton M. Valeriano ${ }^{2}$, John W. Holt', and John M Melack' \\ Institute for Computational Earth System Science', University of California, Santa Barbara CA 93106 USA \\ Instituto Nacional de Pesquisas Espaciais (INPE)², São José dos Campos, SP 12227-010, Brasil \\ Jet Propulsion Laboratory ${ }^{3}$, MS 300-227, Pasadena, CA 91109 USA
}

\section{INTRODUCTION}

During September-November 1995, and again in May-June 1996, high-resolution L-band HH-polarized SAR imagery of the entire Amazon basin was acquired by the National Space Development Agency of Japan's JERS-1 satellite, as part of NASDA's Global Rain Forest Mapping project. In a cooperative effort between NASDA, and NASA's Jet Propulsion Laboratory and Alaska SAR Facility, the approximately 2500 scenes for each date are being mosaicked into digital datasets with 3 arc-second (approximately $100 \mathrm{~m}$ ) resolution, and regional mosaics at the original $12.5 \mathrm{~m}$ resolution are being compiled for selected areas.

The acquisitions were timed to low-water (Sep-Oct 95) and high-water (May-Jun 96) conditions for the main stem of the Amazon River. Individual $75 \times 110 \mathrm{~km}$ low-water scenes at $100 \mathrm{~m}$ resolution may be downloaded from the JPL web site (southport.nasa.jpl.gov/GRFM). Mosaicking of the low-water data has been completed by NASDA and is available on cdrom (ordering information at web site). Mosaicking of the high-water data, and land-cover classification of the joint dataset, are ongoing.

The combined low- and high-water datasets and derived products such as inundation maps will be widely disseminated via internet and cd-rom and should be a valuable resource for scientists involved in basinwide to small watershed studies in many disciplines, as well as an excellent educational tool. This paper presents an overview of major vegetation features visible on the low-water mosaic, and an initial assessment of the backscattering characteristics of representative areas. For each vegetation type described, median backscattering coefficient $\sigma^{\circ}$ and median texture were calculated based on 3 to 5 100-pixel windows. These statistics are valid only for the locales described and are not necessarily representative of basinwide or even regional statistics for that vegetation type. The standard deviation of texture measure of [1] was calculated from the $64(8 \times 8)$ pixels that were averaged to derive each $100 \mathrm{~m}$ pixel. Interpretation of the mosaic was based on ground and aerial surveys carried out during both JERS acquisitions for areas within a 500-km radius from Manaus; on numerous ground and aerial surveys carried out by INPE in Brazil both before and after the acquisitions; and on published sources.

\section{VEGETATION FEATURES}

\section{Savanna}

Although closed forest is the dominant vegetation of the Amazon basin, some types of savanna are conspicuous on the mosaic owing to their low LHH returns. The structure of savanna communities extends across a spectrum with varying proportions of grass, shrub, and tree cover. The terminology used here follows [2], which distinguishes four physiognomic types of Neotropical savanna: savanna grassland (campo limpo, sabana pastizal), in which trees and shrubs are absent; tree and/or shrub savanna (campo sujo, sabana abierto), with $<2 \%$ woody cover; wooded savanna (campo cerrado, sabana cerrada), with $2-15 \%$ woody cover; and savanna woodland (cerrado, sabana boscosa), with $15-40 \%$ woody cover. In all four types, an herbaceous layer of bunchgrasses or sedges is the dominant cover, various degrees of seasonality are present, and fire plays an important role [3].

Savanna grassland and tree/shrub savanna.The two largest savannas on the mosaic are situated at the northern and southern boundaries of the basin: the Roraima-Rupununi savannas, extending from northern Brazil into Guiana (Fig. 1, A), and the Llanos de Mojos of northern Bolivia (B). Smaller areas include the Puciari-Humaita (C); the Sipaliwini, extending from Suriname into the upper Jarí region of Brazil (D); and the Yari of Colombia (E). Outside the Amazon watershed are the Colombian-Venezuelan llanos (F), the Venezuelan Gran Sabana (G), and the savannas of Amapá (H) and Marajó Island (I). A $600 \mathrm{~km}^{2}$ anthropogenic savanna dominated by the fern Pteridium aequilinum is visible on the mosaic in the Serra Parima, near the headwaters of the Orinoco River (J). This area was converted from forest to savanna through repeated burning by Yanomami Indians [4].

The low returns from savanna grassland and tree/shrub savanna contrast with medium or bright returns from forests and woodlands along rivers and drainageways, resulting in the distinctive patterns seen in Figs. 2 and 3. Fig. 2 is typical of the Roraima open grass savanna, with narrow corridors of gallery forests and woodlands dominated by the buriti palm (Mauritia sp.). Sheetwash processes and subsurface erosion on the sandy Rio Branco pediplain result in a dambo-like 


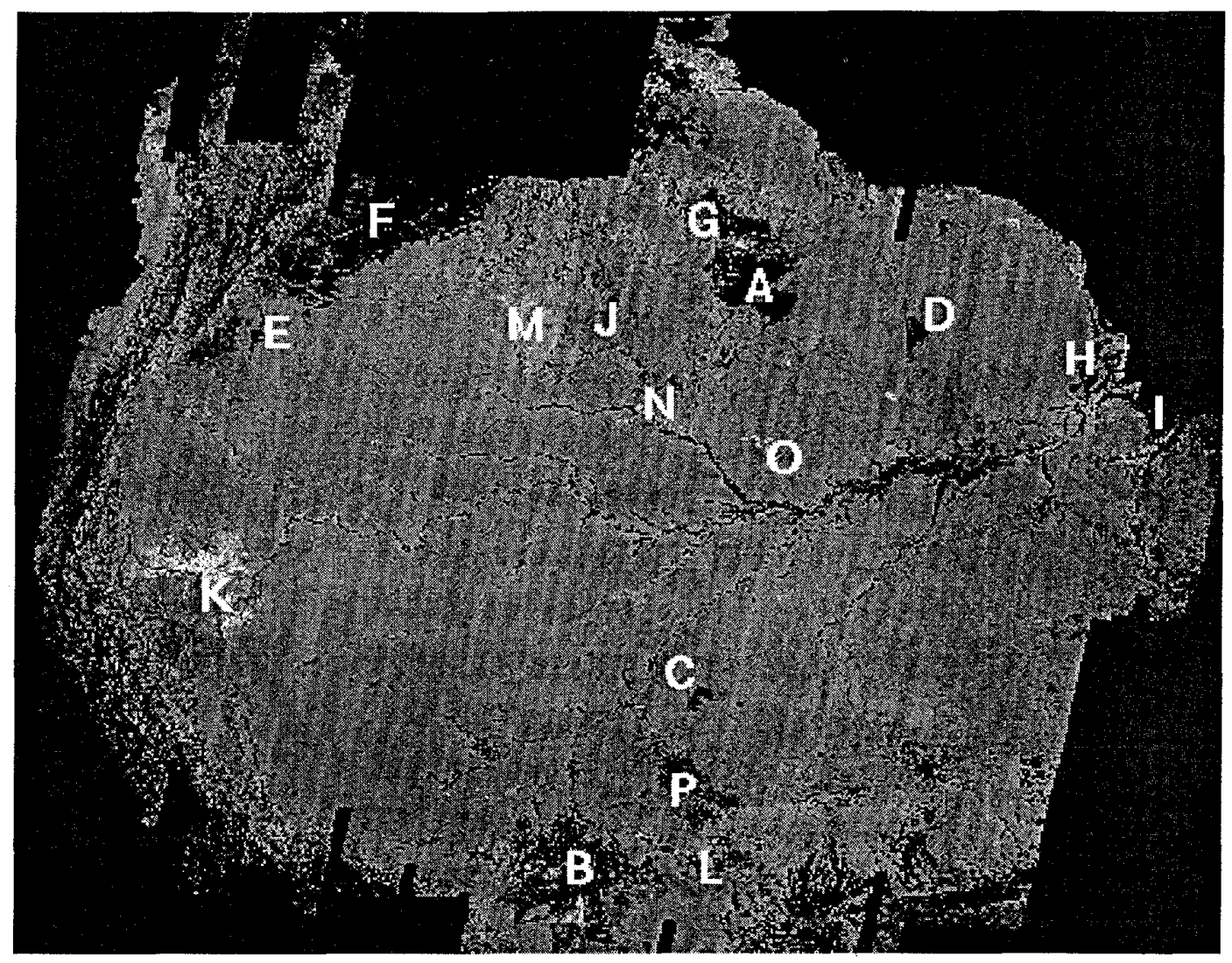

Fig. 1. JERS-1 Amazon low-water mosaic

landscape in which small lakes and swamps are captured by the drainage network [5]. For this region, the timing of the low-water acquisition was within one month of the end of the May-August wet season; buriti stands therefore were inundated, yielding high LHH returns.

In contrast to the Roraima rainfall pattern, the dry season in the Humaitá region extends from June to September; thus forests along drainageways in the Humaitá savanna shown in Fig. 3 were inundated only in a few reaches. The transition from forest to grassland is gradual, with the intermediate zone occupied by wooded savanna and shrub savanna, seen as medium and dark gray tones in Fig. 3. This pattern is interpreted by [6] as a catena extending from well-drained forested soils on slopes bordering streams, to impermeable hydromorphic soils of very high clay content in the interfluves, which support open grassland.

Wooded savanna and savanna woodland. These vegetation types, which are the dominant vegetation of central Brazil, also occur in the southern part of the Amazon basin. Because of the greater amount of woody material, their LHH returns are closer to forest than to grassland on the low-water mosaic. Differentiation from forest might be better on the high-water mosaic, which coincides with the wet season for this region; the more open canopy would result in greater sensitivity to soil moisture changes than in closed-canopy forest.

\section{Wetlands}

The low-water acquisition coincided with an unusually low stage level for the Amazon and Negro rivers $(15.06 \mathrm{~m}$ at the Manaus gauge on 30 Oct 1995). The most conspicuous wetlands on the low-water mosaic are thus not seasonally inundated floodplains, but permanently or semi-permanently inundated areas (some of which occur on low points of seasonally inundated floodplains, e.g. successional communities in old channels and lake beds).

The largest area of flooded vegetation visible on the lowwater mosaic is the extensive forested wetland region of the lower Marañon, Pastaza, and Ucayali rivers in Peru (K). These wetlands occupy a subsiding sedimentary basin, in which interfluvial areas are inundated both by rainfall and by 


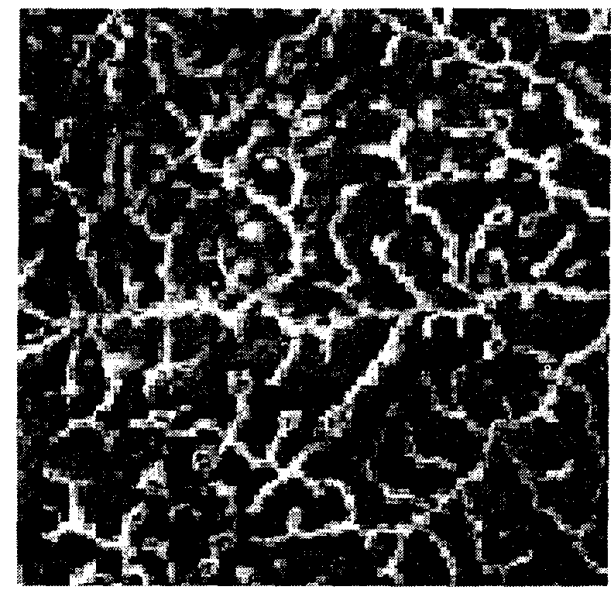

Fig. 2. Roraima savanna $(1.5 \times 1.5 \mathrm{~km})$

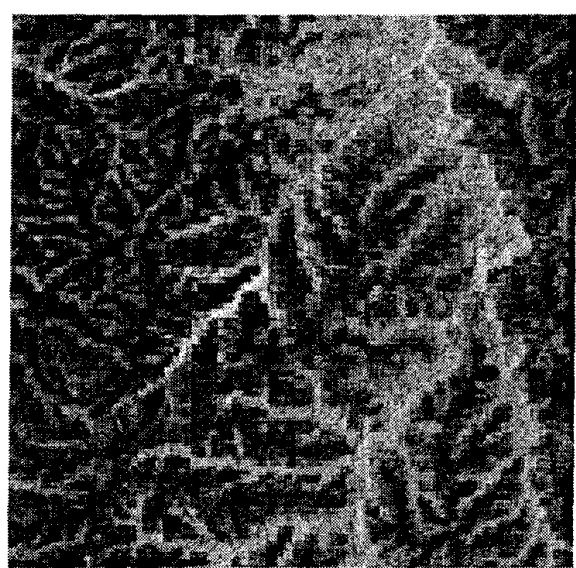

Fig. 3. Humaita savanna $(1.5 \times 1.5 \mathrm{~km})$

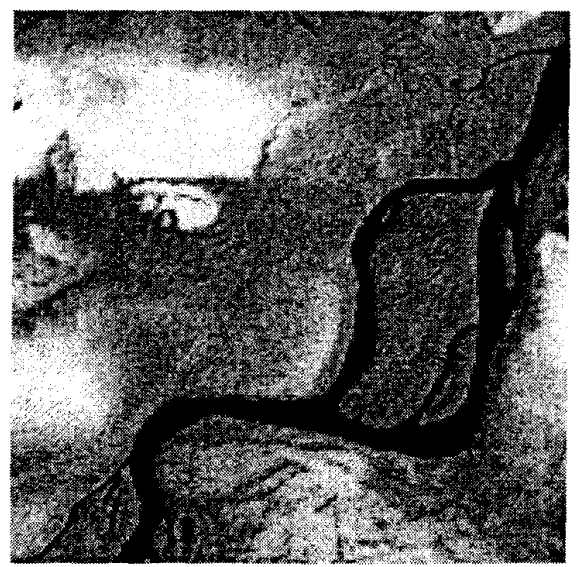

Fig. 4. Palm swamps, Marañon River (25x25 km) river flooding [7]. Because the areas of high backscattering on the mosaic are located in interfluvial depressions rather than directly adjacent to river or stream channels (Fig. 4), and because backscattering is so strong $(-1.2 \mathrm{~dB}$ for the brightest stands), the bright areas most likely are aguajals: palm swamps of depressions permanently flooded with acidic water. A 1-ha survey of an aguajal of the lower Ucayali found that the upper canopy $(>10 \mathrm{~m})$ consisted almost entirely of Mauritia flexuosa crowns [8]. The mosaic shows these palm swamps (and probably other types of inundated or waterlogged forest) occurring over a large area, extending nearly $300 \mathrm{~km}$ along the Marañon and about $200 \mathrm{~km}$ along the Ucayali.

Other large wetland areas conspicuous on the mosaic are the Bolivian llanos (B), the Guaporé Pantanal (L), the Casiquiare wetlands $(\mathrm{M})$, and the wetlands of the BrancoNegro interfluves $(\mathrm{N})$. The latter are a complex mosaic of flooded sedgeland, shrubland, and woodland (including palm swamps), with islands of scrub or woodland growing on white sand (Amazon caatinga or campinarana). Manmade wetlands caused by dams can also be seen on the mosaic; the largest of these is the Balbina Reservoir (O).

\section{Forest}

The matrix within which the savanna and wetland features are visible on the mosaic is, of course, the Amazon rainforest. Examples of several types of forest were located on the mosaic using Radambrasil vegetation maps (Table 1). These forest types vary significantly in terms of structure, biomass, phenology, and floristics, but appear quite similar on the mosaic. Deforestated areas, such as (P) in Rondônia, have a range of signatures comparable to those of the various types of savanna.

\section{BACKSCATTERING CHARACTERISTICS}

The 20 vegetation types for which backscattering statistics were extracted are shown in Table 1, with the results plotted in Fig. 5. The types with $0-2 \%$ woody cover ( 1 to 4 ) are differentiated from woody types both by $\sigma^{\circ}$ and by texture. The lowest median returns $(-17.2 \mathrm{~dB})$ are for a very dry site with sparse senescent grass cover on Marajó Island (3); the high texture value for this site may be because the values are very close to the $18 \mathrm{~dB}$ noise threshold for this dataset; sites 1 and 2 have much lower texture values. For site 4 (shrub savanna), the high texture is more likely to be the result of differences in scattering between pixels with different degrees of shrub cover. The highest $\sigma^{\circ}$ of the nonwoody types $(-11.4 \mathrm{~dB})$ is for an exposed lake bed on the Solimões floodplain, with uniform green grass cover and moist soil (2).

The aguajal stands (20) had both the highest median backscattering $(-1.2 \mathrm{~dB})$ and the smoothest texture. The Balbina stands (19) were nearly as high $(-2.6 \mathrm{~dB})$ but less smooth. Returns for the other inundated forest or woodland (types $13,16,18$ ) were less bright but still quite high: -5.6 to 
Table 1. Vegetation types examined on JERS mosaic

\begin{tabular}{|l|l|}
\hline 1 & Savanna grassland, Roraima savanna \\
\hline 2 & Floodplain grassland, exposed bed of L. Cabaliana \\
\hline 3 & Savanna grassland, Marajó Island \\
\hline 4 & Shrub savanna (campo sujo), Roraima savanna \\
\hline 5 & Open forest, bamboo understory, Acre \\
\hline 6 & Wooded savanna, Chapada dos Parecis, MG \\
\hline 7 & Seasonally decid. forest, Chapada dos Parecis, MG \\
\hline 8 & Open forest, Roraima \\
\hline 9 & Seasonal forest / savanna woodland transition \\
\hline 10 & Non-flooded várzea forest, Solimões floodplain \\
\hline 11 & Dense tropical forest, hilly terrain, Roraima \\
\hline 12 & Dense tropical forest, flat terrain, Roraima \\
\hline 13 & Flooded woodland, Solimões floodplain \\
\hline 14 & Flooded or partly flooded igarapé forest \\
\hline 15 & Flooded shrub or short forest, Unini floodplain \\
\hline 16 & Non-palm flooded areas, Marañon River \\
\hline 17 & Flooded shrub or short forest, Purus floodplain \\
\hline 18 & Flooded tidal forest, Amapá \\
\hline 19 & Flooded dead standing trees, Balbina Reservoir \\
\hline 20 & Flooded palm swamp (aguajal), Marañon River \\
\hline
\end{tabular}

$-4.5 \mathrm{~dB}$. Types 14 and 17 were typical of the brighter areas (other than palm swamps) along the lower reachers of the Juruá and Purus rivers. These sites were at least partly inundated, with successional shrubland or open forest. In the region between the Negro and Japurá rivers, many floodplains (site 15) had darker returns than adjoining forest, an exception to the usual case of brighter returns from flooded forest. These floodplains support scrubby vegetation (on sandy soils), without sufficient woody biomass above water to yield strong double-bounce returns. Although median backscattering for these "dark" floodplains is generally less than $1 \mathrm{~dB}$ lower than that of adjoining forest, the boundary between the two vegetation types is easily distinguished by eye on the mosaic.

The wooded savanna and forest types (5 to 12) all have similar median backscattering, ranging from -7.7 to $-6.7 \mathrm{~dB}$. The open forest (8) and dense forest on highly dissected terrain (11) are differentiated from the rest by texture. In the case of the open forest, gaps and canopy roughness probably contribute to higher texture values. The dense forest (11) differs from another dense forest site (12) primarily in the terrain on which it is situated; both are mapped as the same forest type on Radambrasil maps, but site 12 is located on flat terrain and presents a smooth appearance on the mosaic. Because site 11 is located on terrain with a high drainage density, many slope faces of varying orientation occur within a small area, introducing the variability in the forest returns.

\section{REFERENCES}

[1] P. Swain and S. Davis, Eds., Remote Sensing, the Quantitative Approach, London: McGraw-Hill, 1978.

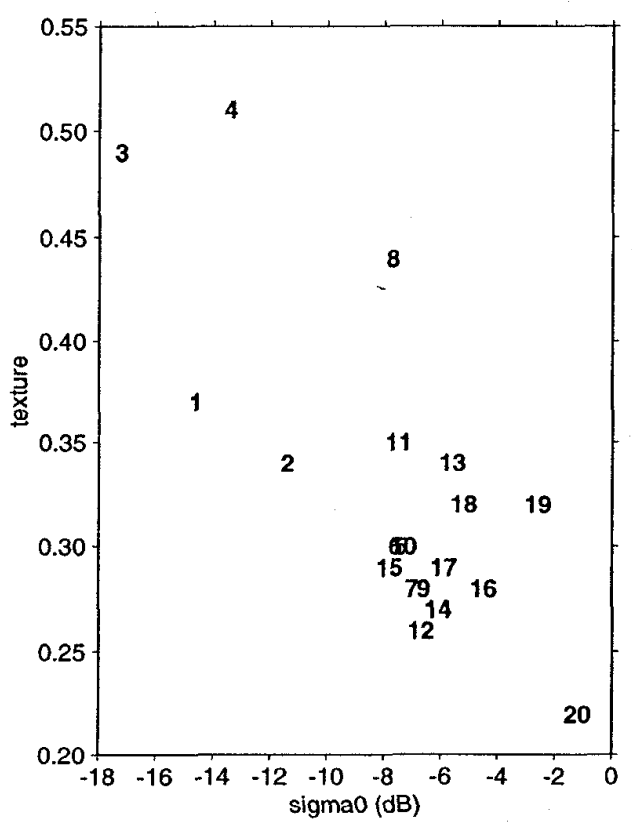

Fig. 5. Median $\sigma^{\circ}$ vs. texture for 20 vegetation types

[2] G. Sarmiento, "The Savannas of Tropical America", in Ecosystems of the World 13: Tropical Savannas. F. Bourlière, Ed. Amsterdam: Elsevier, 1983, pp. 245-288.

[3] G. Sarmiento, The Ecology of Neotropical Savannas. Cambridge, Mass.: Harvard Univ. Press, 1984.

[4] B. Nelson, "O índio e El Niño: florestas afetadas pelo fogo natural na Amazônia,". Resumos, $38^{\circ}$ Congresso Nacional de Botânica, Crato, Ceará, July-August 1997.

[5] C.E.R. Schaefer, "Ecogeography and human scenario in northeast Roraima, Brazil", Ciência e Cultura: J. Braz. Assoc. Adv. Sci., vol. 49, pp. 241-252, July/Aug 1997.

[6] E. Braun and J. Ramos, "Estudos agrogeológica dos campos Puciari-Humaitá," Rev. Bras. Geogr., vol. 21, pp. 443-497.

[7] J.F. Dumont, S. Lamotte, and F. Kahn, "Wetland and upland forest ecosystems in Peruvian Amazonia: Plant species diversity in the light of some geological and botanical evidence," Forest Ecol. Manage., vol. 33/34, pp. 125-139, 1990.

[8] F. Kahn and K. Mejia, "Palm communities in wetland forest ecosystems of Peruvian Amazonia," Forest Ecol. Manage., vol. 33/34, pp. 169-179. 